\title{
Effects of calcitonin gene-related peptide on the non- adrenergic inhibitory potentials in the intestinal smooth muscle cells of the guinea pig
}

\author{
Hiromichi OHKaWA \\ Department of Physiology, Yamaguchi University School of Medicine, Ube \\ Japan
}

\begin{abstract}
Ohkawa, H. Effects of calcitonin gene-related peptide on the non-adrenergic inhibitory potentials in the intestimal smooth muscle cells of the guinea pig. Japanese Tournal of Smooth Muscle Research, 25(3), 98-96, 1989 _ Effects of calcitonin gene-related peptide (CGRP) on the spontaneous and evoked contractions in the duodenal and ileal preparations, the spontaneous action potentials and the non-adrenergic non-cholinergic inhibitory potentials (NANC i.p.s) in the longitudinal smooth muscle cells of the guinea-pig duodenum and ileum were examined. Preparations were pretreated with atropine $(1 \mu \mathrm{M})$ and guanethidine ( $5 \mu \mathrm{M})$. CGRP $(26 \mathrm{nM})$ was found to inhibit spontaneous and evoked contractions. The resting membrane potential of the longitudinal smooth muscle was not altered but the frquency of spontaneous action potentials was decreased by the treatment with CGRP (6-104 $\mathrm{nM})$. Field stimulation evoked the NANC i.p.s and the pretreatment with atropine $(1 \mu \mathrm{M})$ and guanethidine $(5 \mu \mathrm{M})$ caused an increase in the amplitude of the NANC i.p.s in the longitudinal smooth muscle. However, CGRP (6-104 nM) did not change the amplitude of the NANC i.p.s. The rebound excitation in the longitudinal muscle membrane was inhibited by CGRP. The single spike activity of the myenteric neurons in the duodenum was not affected by CGRP (26-104 $\mathrm{nM})$. The results suggest that CGRP inhibits the intestinal motility by non-neurogenic NANC manner and does not activate the NANC inhibitory neurons in intestine.
\end{abstract}

\section{Introduction}

Capsaicin has been shown to produce a transient relaxation of the longitudinal muscle of the rat isolated duodenum (Maggi et al., 1986a, b). Maggi et al. (1986a, b, 1987) emphasized the following hypothesis on the action of capsaicin-induced relaxation: (1) capsaicin stmulates certain sensory fibers of extrinsic origin leading to release of calcitonin gene-related peptide (CGRP). (2) released CGRP porduces a transient relaxation of the duodenum both directly and indirectly by activating an intramural non-adrenergic non-cholinergic (NANC) inhibitory neuron(s) which in turn releases a substance porducing a duodenal relaxation.

CGRP has been found to cause relaxation in the rat duodenum (Maggi et al., 1986b), the guinea pig ileum (Barthó et al., 1987 ; Takaki et al., 1986), the guinea pig ureter (Hau et al., 1986), the rat tail artery (Kline and Pang, 1988) and the human coronary artery (Ezra et al., 
1987) and to excite the myenteric neurons in the guinea pig ileum (Palmer et al., 1986). On the other hand, the widespread distribution of CGRP throughout the central and peripheral nervous system, especially in sensory nerves, has been demonstrated immunocytochemically (Gibson et al., 1984 ; Kawai et al., 1985 ; Ju et al., 1987 ; Skofitsch and Jacobwitz, 1985 ; Lundberg et al., 1985). CGRP-like immunoreactivity is also distributed extensively in the myenteric and submucous plexuses of the intestine (Clague et al., 1985; Furness et al., 1985 ; Fehér et al., 1986). Based on these results, it is supeculated that CGRP may act in local regulation of gastrointestinal tract through a neurotransmitter or neuromodulator function. The aim of the present study was to investigate the effects of CGRP on the NANC i.p.s in intestinal smooth muscle cells.

\section{Methods}

Segments of intestine were removed from the ileum $10-20 \mathrm{~cm}$ from the ileo-cecal junction and the duodenum $1 \mathrm{~cm}$ from the pylorus of the stomach of adult guinea-pigs $(300-400 \mathrm{~g})$ that had been stunned by a blow to the head and exsanguinated. The segment was opened along the mesenteric border and full-thickness strips $(5 \mathrm{~mm} \times 4 \mathrm{~mm})$ were cut parallel to the longitudinal direction. These segments were pinned on a rubber plate in a $2-\mathrm{ml}$ organ bath superfused with Krebs solution at $37^{\circ} \mathrm{C}$ and gassed with $95 \% \mathrm{O}_{2}-5 \% \mathrm{CO}_{2}$.

The membrane electrical activity of longitudinal muscle cells was recorded with intracellular microelectrodes placed less than $1 \mathrm{~mm}$ from one of the stimulating electorodes, in response to rectangular pulses (useally $0.5 \mathrm{msec}$ duration at constant strength). Values of measured parameters on muscle membrane and inhibitory potentials (i.p.s) were expressed as the mean $\pm \mathrm{SD}$ ( $\mathrm{n}=$ number of penetration of the microelectrode or number of observed i.p.s). The mean values of the amplitude of i.p.s in various solutions were obtained druing 5-15 min after starting the perfusion. The electrical activity of the myenteric neurons in the duodenum was recorded with extracellular microelectrodes. The recording method of the electrical activity of the myenteric neurons was the same to that described previously (Ohkawa, 1989). The mechanical activity of the segment was recorded longitudinally by the conventional mentods. Composition of the Krebs solution in $\mathrm{mM}$ was: $\mathrm{NaCl} 122, \mathrm{KCl} 4.9, \mathrm{CaCl}_{2} 2.5, \mathrm{MgCl}_{2}$ 1.2, $\mathrm{NaHCO}_{3}$ 15.5, $\mathrm{KH}_{2} \mathrm{PO}_{4} 1.2$ and glucose 11.5. The drugs used are as follows: atropine sulfate, guanethidine sulfate (Tokyo Kasei) and synthetic form of rat CGRP (Peptide Institute). The preparations were treated with atropine $1 \mu \mathrm{M}$ and guanethidine $5 \mu \mathrm{M}$ before and during the experiments on the effect of CGRP except some experiments.

\section{Results}

\section{Effects of CGRP on the spontaneous and evoked contractions in the intestinal smooth muscles}

Tissues obtained from the duodenum, ileum and taenia coli exhibited the spontaneous contractile activity. After treatment with atropine $(1 \mu \mathrm{M})$ and guanethidine $(5 \mu \mathrm{M})$, slight decrease in the frequency of spontaneous phasic contraction was observed in the duodenal preparation. Additional application of CGRP $(26 \mathrm{nM})$ lowered the amplitude of the phasic contraction and the tone level of all preparations. Fig. 1 shows the relaxant effect of CGRP on 


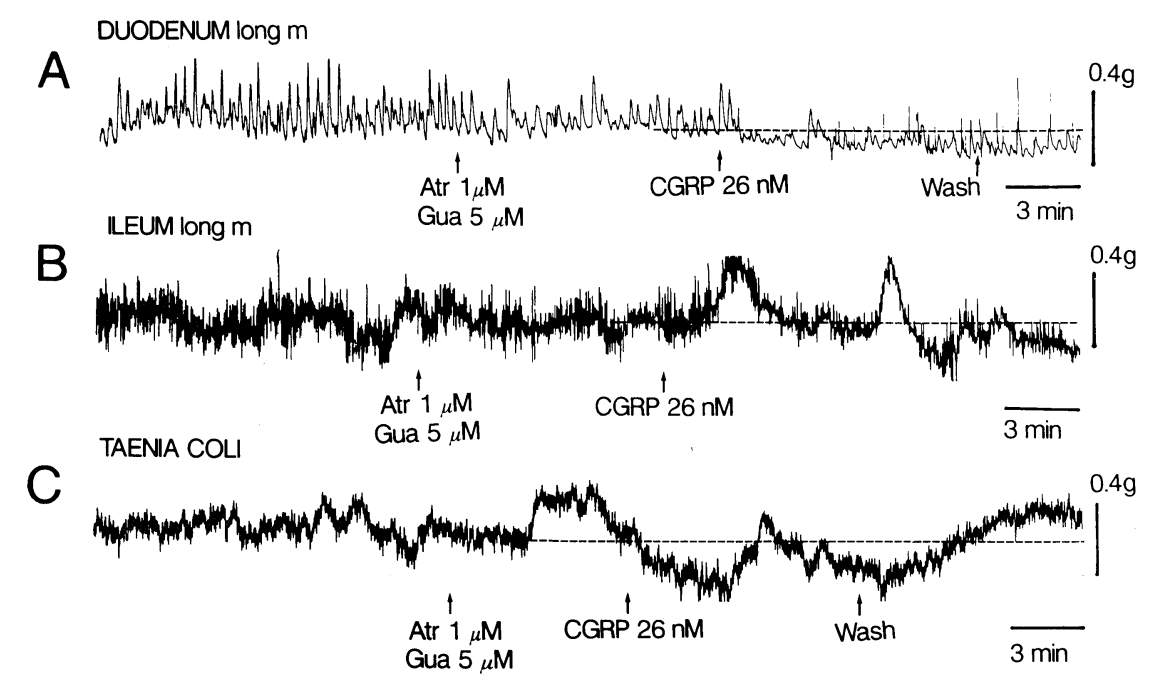

Fig. 1. Effects of CGRP on the spontaneous mechanical activity of the intestinal segments. A, duodenum, B, ileum and $\mathrm{C}$, taenia coli.

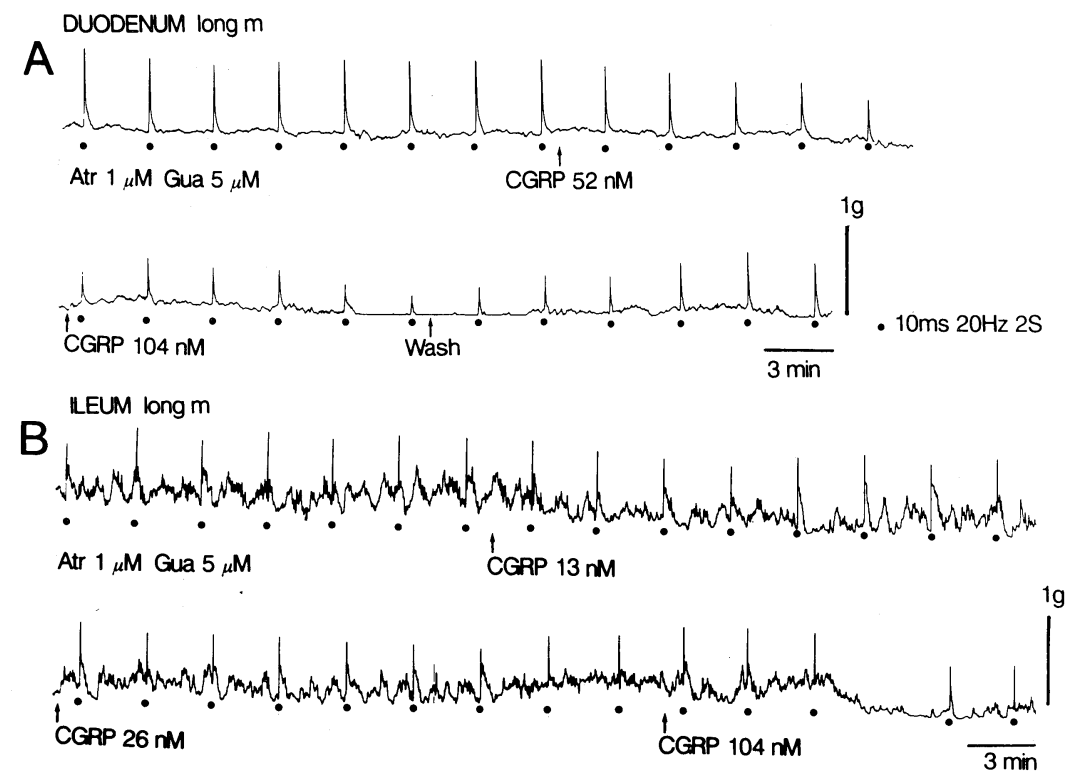

Fig. 2. Effects of CGRP on the evoked contraction of the duodenum (A) and ileum (B). Stimulation ; $10 \mathrm{msec}, 20 \mathrm{~Hz}$ for $2 \mathrm{sec}$.

the spontaneous contractile activity in various regions of the intestinal tract.

The duodenal and ileal preparations produced a phasic contraction in response to field stimulation ( $10 \mathrm{msec}, 20 \mathrm{~Hz}, 2 \mathrm{sec}$ ). When the interval of stimulation was $3 \mathrm{~min}$, the amplitude of phasic contractions in the duodenal and ileal preparations was constant during in normal and pretreatment with atropine $(1 \mu \mathrm{M})$ and guanethidine $(5 \mu \mathrm{M})$ solutions (Fig. 2). CGRP (13-104 $\mathrm{nM}$ ) decreased the amplitude of these evoked contractions in both duodenal and ileal preparations. 


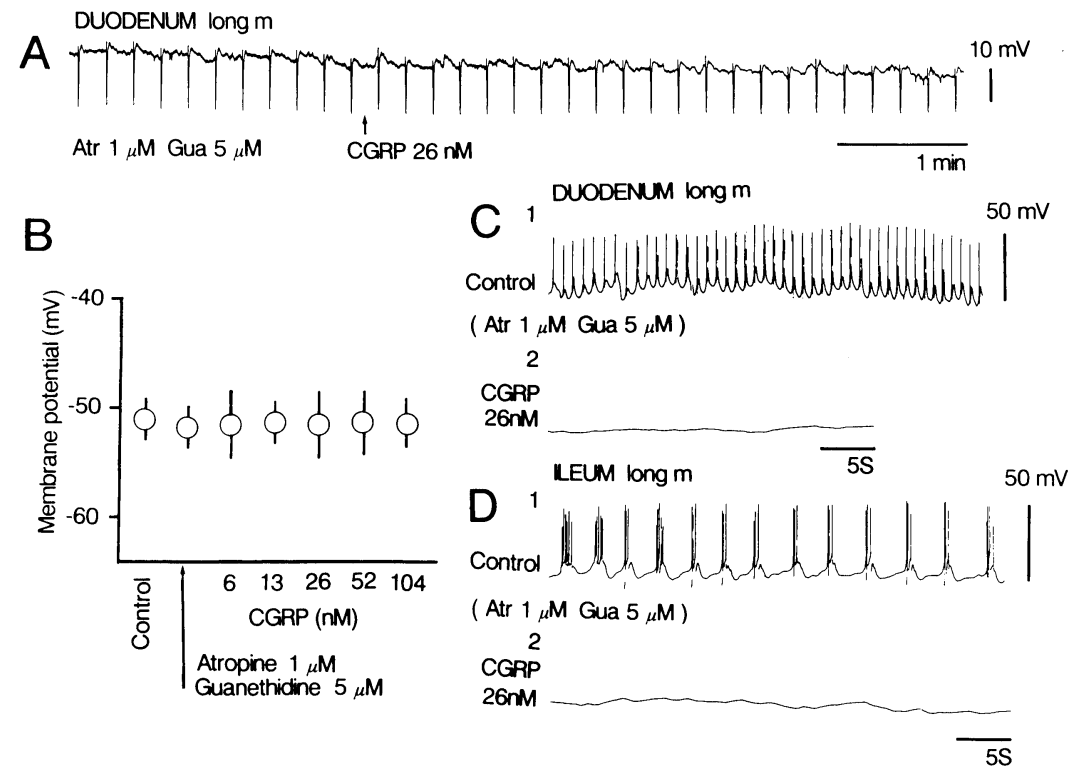

Fig. 3. Effects of CGRP on the resting membran potential and the spontaneous action potentials in the intestinal smooth muscles. A, longitudinal smooth muscle of the duodenum. The NANC i.p.s were evoked. B, changes in the resting membrane potential in the longitudinal smooth muscle cells of the duodeunm. C, spontaneous action potentials of the longitudinal smooth muscle of the duodenum befor (1) and after (2) CGRP. D, spontaneous action potentials in the longitudinal smooth muscle of the ileum before (1) and after (2) CGRP.

2. Effects of CGRP on the spontaneous electrical activity of the intestinal smooth muscles

The resting membrane potential of the longitudinal smooth muscle cells was $-51.2 \pm 2.5$ $\mathrm{mV}(\mathrm{n}=25)$. The membrane potential was slightly increased in the atropine $(1 \mu \mathrm{M})$ and guanethidine $(5 \mu \mathrm{M})$ solution. Fig. $3 \mathrm{~A}$ shows the membrane potential of the longitudinal smooth muscle before and after the application of CGRP $26 \mathrm{nM}$. Changes in the resting membrane potentials in various concentrations of CGRP (6-104 nM) were summarized in Fig. 3B. There were no significant differences between these values. Fig. $3 \mathrm{C}$ and $\mathrm{D}$ show the effects of CGRP (26 nM) on the spontaneous activity in the longitudinal smooth muscle cells of the duodenum and ileum. CGRP (26-104 nM) was found to inhibit the generation of spontaneous action potentials. In some preparations the frequency of spontaneous action potentials was decreased.

\section{Effects of CGRP on the NANC inhibitory potentials in the intestinal smooth muscles}

Field stimulation with single pulses across the duodenal preparation evoked inhibitory potentials (i.p.s) (Fig. 4, A1, B1 and C1). The parameters on the evoked i.p.s were similar to those reported previously (Ohkawa, 1986). Treatment with atropine $(1 \mu \mathrm{M})$ and guanethidine (5 $\mu \mathrm{M}$ ) increased the amplitude of the i.p.s (Fig. 4, A2, B2 and C2), up to about $120 \%$ of control. After the pretreatment with atropine and guanethidine, effects of CGRP on the NANC i.p.s were examined. As shown in Fig. 4 (A3, B3 and C3), the characteristics of these NANC i.p.s 


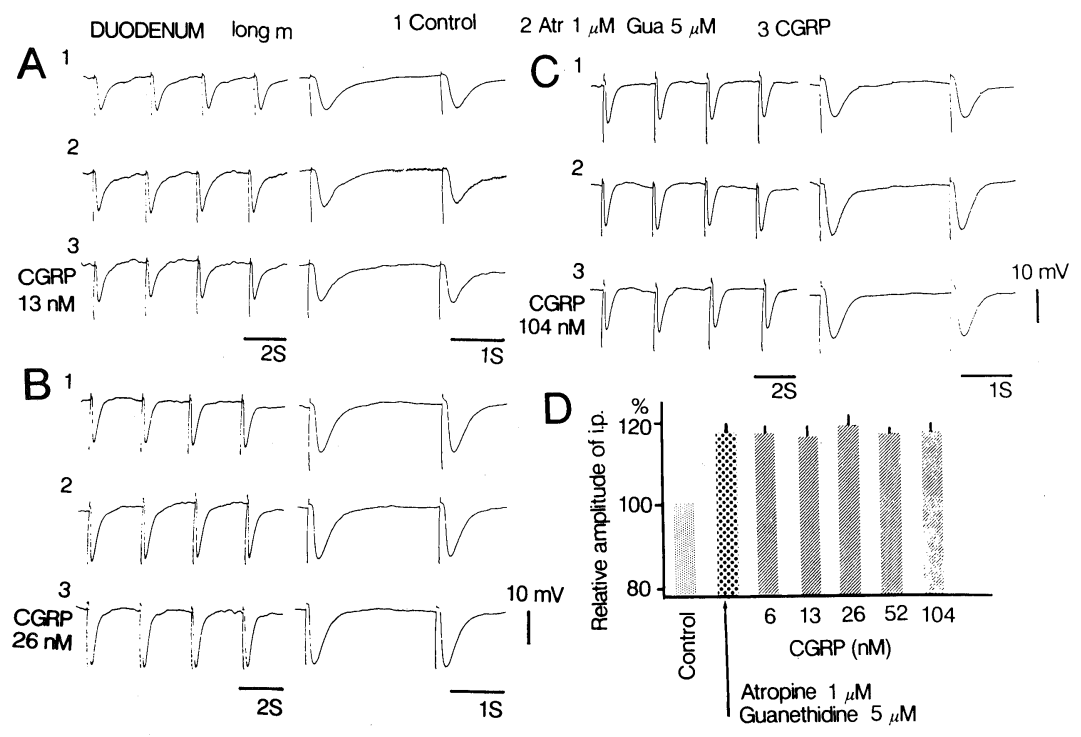

Fig. 4. Effects of CGRP on the NANC i.p.s in the longitudinal smooth muscles of the duodenum. In $\mathrm{A}, \mathrm{B}$ and $\mathrm{C}, 1$; control, 2 : atropine $1 \mu \mathrm{M}$ and guanethidine $5 \mu \mathrm{M}$ and 3 ; CGRP (13-104 $\mathrm{nM})$. D, changes in the relative amplitude of the NANC i.p.s obtained from the longitudinal smooth muscle cells.
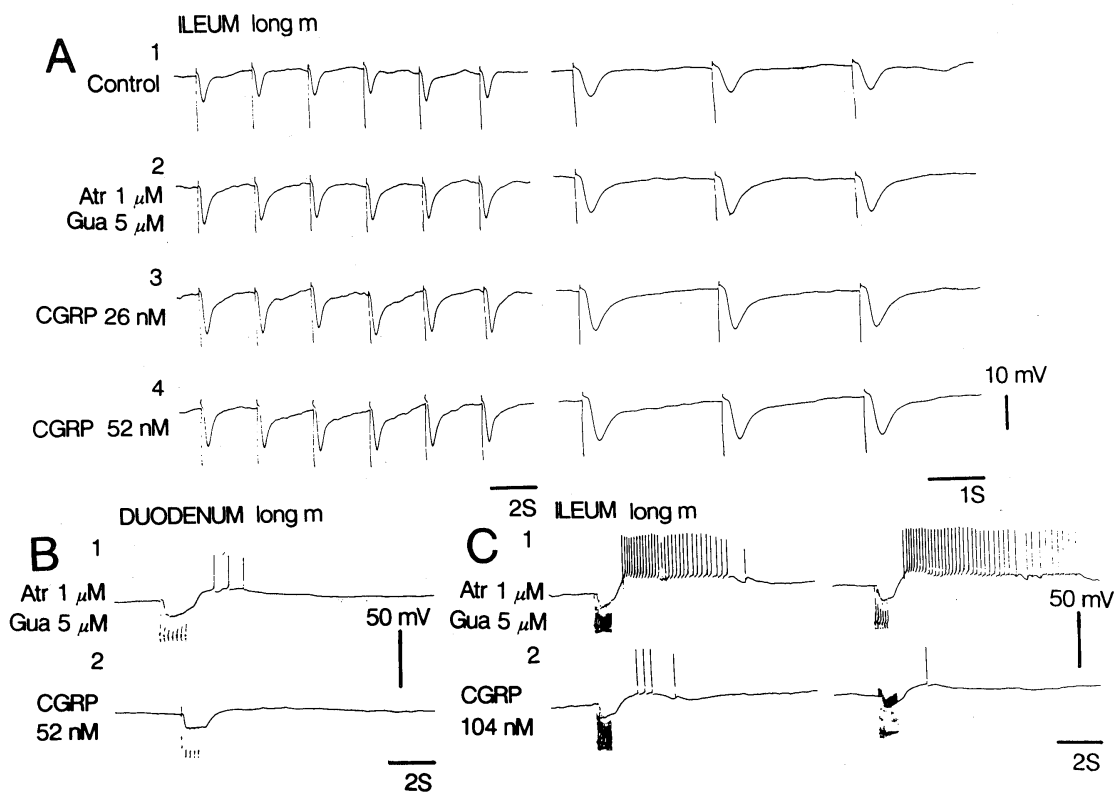

Fig. 5. Effects of CGRP on the NANC i.p.s and the rebound excitation in the intestinal smooth muscle cells. A, NANC i.p.s in the longitudinal smooth muscle of the ileum. B and C, changes in the rebound excitation in the longitudinal smooth muscle cells of the duodenum (B) and the ileum (C). Stimulation; $0.5 \mathrm{msec}, 10-20 \mathrm{~Hz}, 5-20$ pusles. 
were not changed by the application of CGRP (6-104 nM). Changes in the mean relative amplitude of the NANC i.p.s were summrarized in Fig. 4D. Similar results on the effects of CGRP (26-104 nM) on the NANC i.p.s were obtained from the ileal preparation (Fig. 5A).

In Fig. 5B, effects of CGRP on the rebound excitation in the longitudinal smooth muscle cells of the duodenal and ileal preparations resulting by repetitive field stimulation $(0.5 \mathrm{msec}$, 10-20 Hz, 5-50 pulses). The cessation of field stimulation produced an after-depolarization and action potentials were generated at high frequency superimposed on the after-depolarization (Fig. 5, B1 and C1). Treatment with CGRP (52-104 nM) inhibited the rebound excitation, that is, the amplitude of the after-depolarization was reduced and the generation of action potentials was inhibited (Fig. 5, B2 and C2).

\section{Effects of CGRP on the electrical activity of the myenteric neurons}

Single spike activity of the myenteric neurons in the duodenum was recorded in normal solution. The frequency of the single spikes was not affected by CGRP (26-104 nM) in the presence and the absence of atropine $(1 \mu \mathrm{M})$ and guenethidine $(5 \mu \mathrm{M})$.

\section{Discussion}

It has been suggested that CGRP released from the capsaicin-sensitive sensory nerve fibers in intestinal wall due to exogenously applied capsaicin and CGRP produced a transient relaxation of intestine both directly and indirectoy by activating an intramural NANC neuron (s) which in turn release a substance producing an intestinal relaxation (Maggi et al., 1986a, b, 1987).

In the present experiments, spontaneous mechanical activity of the duodenal and ileal preparations was slightly inhibited by CGRP in the presence of atropine and guanethidine. Thus, CGRP exhibits NANC inhibition on the motility of intestine. In the presence of atropine and guanethidine, the generation of spontaneous action potentials in the intestinal smooth muscle cells was inhibited by CGRP without changes in the resitng membrane potential.

The amplitude of the NANC i.p.s was increased by the pretreatment with atropine and guanethidine. As described before (Ohkawa, 1986), this increase in the amplitude of the NANC i.p.s may be due to block the cholinergic inhibitoyry modulation on the NANC inhibitory neurons. The amplitude of the NANC i.p.s was not affected by the treatment with CGRP (6$104 \mathrm{nM}$ ) and CGRP-induced NANC i.p.s were also not observed. These results strongly suggest that CGRP has no effects on the activity of the NANC inhibitory neurons while exhibits the non-neurogenic NANC relaxation due to inhibit the generation of action potentials without changes in the resting membrane potential of the intestinal smooth muscle cells.

Recently Kline and Pang (1988) demonstrated that CGRP inhibited the norepinephrineinduced contraction of the rat tail artery and suggest that CGRP exerts its effect by inhibiting the mobilization of intracellular $\mathrm{Ca}^{++}$. In the present experiments, evoked contractions of the duodenal and ileal preparations were inhibited by CGRP. Furthermore, the rebound excitation in the intestinal muscle cells after the cessation of repetitive stimulation was also inhibited by CGRP. It is considered that these inhibitory effects of CGRP may relate to inhibition of the mobilization of intracellular $\mathrm{Ca}^{++}$and of the entry of $\mathrm{Ca}^{++}$. The action site of CGRP is not clear but, in the gastric smooth muscle cells, it was suggested that CGRP-induced relaxation 
was mediated by distinct receptors for CGRP (Maton et al., 1986).

The exitatory effect of CGRP on myenteric neurons (AH/Type 2) has been found (Palmer et al, 1986). However, the single spike activity recorded from the myenteric neurons in the duodenum was not enhanced by CGRP. Further study on the role of CGRP as a neuromodulator is required.

\section{References}

Barthó, L., Lembeck, F. and Holzer, P. (1987). Calcitonin gene-related peptide is a potent relaxant of intestinal muscle. Eur. J. Pharmacol. 135 : 449-451.

Clague, J.R., Sternini, C. and Brecha, N.C. (1985). Localization of calcitonin gene-related peptidelike immunoreactivity in neurons of gastrointestinal tract. Neurosci. Lett. 56 : 63-68.

Ezra, D., Laurindo, R.M., Goldstein, D.S., Goldstein, R.E. and Feuerstein, G. (1987). Calcitonin generelated peptide: a potent modulator of coronary flow. Eur. J. Pharmacol. 137 : 101-105.

Fehér, E., Burnstock, G., Varndell, I.M., Polak, J.M. (1986). Calcitonin gene-related peptide-immunoreactive nerve fibers in the small intestine of the guinea-pig: electron-microscopic immunocytochemistry. Cell. Tiss. Res. 245 : 353-358.

Furness, J.B., Costa, M., Gibbins, I.L. Llewellyn-Smith, I.J. and Oliver, J.R. (1985). Neurochemically similar myenteric and submucous neurons directly traced to the mucosa of the small intestine. Cell. Tiss. Res. 241 : 155-163.

Gibson, S.J., Polak, J.M., Bloom, S.R. et al. (1984). Calcitonin gene-related peptide immunoreactivity in the spinal cord of man and eight other species. J. Neurosci. 4:3101-3111.

Hau, X.Y., Kinn, A.C. and Lundberg, J.M. (1986). Capsaicin-sensitive nerves and ureteric motility : opposing effects of tachykinins and calcitonin gene-related peptide. Acta physiol. Scand. 128: $317-318$.

Ju, G., Hökfelt, T. Brodin, E., Fahrenkrug, J., Fischer, J.A., Frey, P., Elde, R.P. and Brown, J.C. (1987). Primary sensory neurons of the rat showing calcitonin gene-related peptide immunoreactivity and their relation to substance $\mathrm{P}_{-}$, somatostatin-, galanin-, vasoactive intestinal peptide-, and cholecystokinin-immunoreactive ganglion cells. Cell. Tiss. Res. 247 : 417-431.

Kawai, Y., Takami, K., Shiosaka, S., Emson, P.C., Hillyard, C.J., Girgis, S., McIntyre, I. and Tohyama, M. (1985). Topographic localization of calcitonin gene-related peptide in the rat brain : an immunohistochemical analysis. Neuroscience, 15 : 747-763.

Kline, L. and Pang, P. (1988). Calcitonin gene-related peptide relaxed rat tial artery helical strips in vitro in an intracellular calcium-dependent manner. Eur. J. Pharmacol. 150: 233-238.

Lundberg, J.M., Franco-Cereceda, A. Hua, S. Hökfelt, T. and Fischer, J.A. (1985). Coexistence of substance $\mathrm{P}$ and calcitonin gene-related peptide-like immunoreactivities in sensory nerves in relation to cardiovascular and bronchioconstrictor effects of capsaicin. Eur. J. Pharmacol. 108: 315-319.

Maggi, C.A., Manzini, S., Giuliani, S., Santicioli, P. and Meli, A. (1986a). Extrinsic origin of the capsaicin-sensitive innervation of rat duodenum: possible involvement of calcitonin generelated peptide (CGRP) in the capsaicin-induced activation of intramural non-adrenergic non-cholinergic neurons. Naunyn-Schmied. Arch. Pharmacol. 334 : 172-180.

Maggi, C.A., Santicioli, P., Manzini, S. and Meli, A. (1986b). Capsaicin activates neurogenic nonadrenergic non-cholinergic relaxation of the isolated rat duodenum. Eur. J. Pharmacol. 120: 367-370.

Maggi, C.A., Meli, A. and Santicioli, P. (1987). Four motor effects of capsaicin on guinea-pig distal colon. Br. J. Pharmacol. 90 : 651-660.

Maton, P.N., Sutliff, V.E. Zhou, Z.C., Gardner, J.D., and Jensen, R.T. (1986). Charaterization of receptors for calcitonin-gene-related peptide (CGRP) on gastric smooth muscle cells. 
Gastroenterol. 90 : 1537.

Ohkawa, H. (1986). Cholinergic modulation and effects of dynorphin on the non-adrenergic inhibitory potentials in the guinea-pig dudodenum. Jpn. J. Physiol. 36 : 699-711.

Ohkawa, H. (1989). Spread of the single spike activity in the myenteric plexus of the guinea-pig duodenum. Jpn. J. Smoth Muscle Res. 25: 39-46.

Palmer, J.M., Schemann, M., Tamura, K., Wood, J.D. (1986). Calcitonin gene-related peptide excites myenteric neurons. Eur. J. Pharmacol. 132: 163-170.

Skofitsch, G. and Jacobwitz, D.M. (1985). Calcitonin gene-related peptide: detailed immunohistochemical distribution in the central nervous system. Peptide. 6 : 721-745.

Takaki, M., Jin, J.G. and Nakayama, S. (1986). Possible involvement of calcitonin gene-related peptide (CGRP) in non-cholinergic non-adrenergic relaxation induced by mesenteric nerve stimulation in guinea pig ileum. Brain Res. 478: 199-203.

\section{(平成元年 7 月 26 日 受付)}

